\title{
A Hydraulic Analysis of Shock Wave Generation Mechanism on Flat Spillway Chutes through Physical Modeling
}

\author{
Muhammad Kaleem Sarwar ${ }^{1}$, Muhammad Atiq Ur Rehman Tariq ${ }^{2,3, * \mathbb{D} \text {, Rashid Farooq }}{ }^{4}$ (D), \\ Hafiz Kamran Jaleel Abbasi ${ }^{1}$, Faraz Ul Haq ${ }^{1}$, Ijaz Ahmad 1 ${ }^{\mathbb{D}}$, Muhammad Izhar Shah ${ }^{5}$, \\ Anne. W. M. Ng ${ }^{6}$ and Nitin Muttil ${ }^{2,3, *(D)}$
}

Citation: Sarwar, M.K.; Tariq, M.A.U.R.; Farooq, R.; Abbasi, H.K.J.; Haq, F.U.; Ahmad, I.; Shah, M.I.; Ng, A.W.M.; Muttil, N. A Hydraulic Analysis of Shock Wave Generation Mechanism on Flat Spillway Chutes through Physical Modeling. Hydrology 2021, 8, 186. https:// doi.org/10.3390/hydrology8040186

Academic Editors: Carmelina

Costanzo, Tommaso Caloiero and Roberta Padulano

Received: 29 November 2021 Accepted: 16 December 2021 Published: 17 December 2021

Publisher's Note: MDPI stays neutral with regard to jurisdictional claims in published maps and institutional affiliations.

Copyright: (c) 2021 by the authors. Licensee MDPI, Basel, Switzerland. This article is an open access article distributed under the terms and conditions of the Creative Commons Attribution (CC BY) license (https:/ / creativecommons.org/licenses/by/ $4.0 /)$.
1 Centre of Excellence in Water Resources Engineering, University of Engineering and Technology, Lahore 54890, Pakistan; eng_Kaleem@yahoo.com (M.K.S.); kami.abbasi019@gmail.com (H.K.J.A.); engraraz@uet.edu.pk (F.U.H.); engr.ijaz786@gmail.com (I.A.)

2 College of Engineering and Science, Victoria University, Melbourne 8001, Australia

3 Institute for Sustainable Industries \& Liveable Cities, Victoria University, P.O. Box 14428, Melbourne 8001, Australia

4 Department of Civil Engineering, International Islamic University, Islamabad 44000, Pakistan; rashidmeo50@gmail.com

5 Department of Civil Engineering, Abbottabad Campus, COMSATS University Islamabad, Abbottabad 22060, Pakistan; mizharshah.civ@uetpeshawar.edu.pk

6 College of Engineering, IT \& Environment, Charles Darwin University, Darwin 0810, Australia; Anne.Ng@cdu.edu.au

* Correspondence: Atiq.Tariq@yahoo.com (M.A.U.R.T.); Nitin.Muttil@vu.edu.au (N.M.)

Abstract: Shock waves are generated downstream of spillways during flood operations, which have adverse effects on spillway operations. This paper presents the physical model study of shock waves at the Mohmand Dam Spillway project, Pakistan. In this study, hydraulic analysis of shock waves was carried out to investigate its generation mechanism. Different experiments were performed to analyze the rooster tail on a flat spillway chute and to examine the factors affecting the characteristics of the rooster tail. The study results show that shock wave height is influenced by spillway chute slope, pier shape, and flow depth. Moreover, the height of the shock wave can be minimized by installing a semi-elliptical pier on the tail part of the main pier. Further modifications in the geometry of the extended tail part of the pier are recommended for the elimination of the shock wave. Based on observed data collected from the model study, an empirical equation was developed to estimate the shock wave height generated on the flat slope spillway chutes $\left(5^{\circ}\right.$ to $\left.10^{\circ}\right)$.

Keywords: shock wave; spillway; spillway pier; flat chute; physical modeling

\section{Introduction}

Concerns related to the effects of unpredictably high flows entering reservoirs, especially considering possible increased rainfall intensities, have led to a renewed general interest in reservoir spillway design. In the spillways, gates are mounted onto the crest of a free spillway that controls the head, discharge, reservoir volume, and reservoir level increase. The addition of these gates adds some new complex issues to the hydraulic subjects [1-3]. According to Ansar et al. [4], not all flow conditions can occur at most spillways; thus, flow conditions at a gated spillway tend to become controlled when the gate opening $G_{0}$ is smaller than the critical depth $y_{c}$ and submerged when the tailwater depth $h$ is greater than $y_{c}$. Moreover, they developed generalized flow rating equations based on field flow measurements at the gated spillway. Al-Mansori et al. [5] found that, with increasing hydraulic head up to seven times that of the design head, the flow separation zone grows linearly.

Among gate discharge coefficients, the gate's location above the spillways, and separation of flow profile, the spillway transverse flows and waves are lesser-known issues. These 
waves are called by different names such as shock waves, lateral shock waves, and rooster tail waves $[6,7]$. The mechanism that induces the rooster tail is the gathering pressure generated by the joint flow. During that process, the kinetic energy of the diffused flow is converted into pressure energy and is transported to the bottom, subsequently. Thus, variations in the pressure of the spillway bottom can be used to reflect the intensity of the rooster tail [6]. Likewise, shock waves are frequently generated in dam spillways by uniform flow disturbances due to the presence of spillway piers, curves, or changes in the cross-section of spillway chutes [6,8,9]. Consequently, local maxima inflow depth are produced, and their magnitude can be much greater than the incoming uniform depth. This has important practical implications in the dimensioning of the chute walls, which must be designed with greater height to adequately convey the flow, with the obvious consequences in terms of magnitude and cost [10]. According to Jiang and Xiang [11], shock waves behind the pier may result in poor hydraulic performance such as reduced discharge capacity, erosion and swell, increased aeration, and asymmetry of water flow in the steep groove. The shock wave generated at the end of the pier causes the water surface downstream of the sluice to become a cross-shaped rhombic wave, which causes the water flow to be partially high and may lead to overflow. For spillways, overflow may result in erosion of the spillway foundation; thus, to prevent the overflow of water, it is necessary to increase the sidewall.

Moreover, the design of the spillway must tend to the constant cross-section and slope to approach uniform flow and thus avoid the shock wave phenomenon. However, these geometric particularities are frequently unavoidable due to the topographical and/or geological characteristics of the dam and spillway site [10]. Thus, shock waves can be generally grouped into different categories [6]. In slit-type energy dissipaters, a shock wave is generated due to the contraction of the channel section $[5,12]$. The second kind of shock wave is induced in stepped spillways due to their steep chute slope [13-16]. Rajaratnam [13] noted that the second kind of shock wave occurs during low flows. In another study, Chanson [17] observed the effect of step geometry and flow regime on the generation of a shock wave. Similarly, Carnacina et al. [16] conducted an experimental study to observe shock wave height on the stepped spillway and concluded that shock wave height is low in steep chutes as compared to flat ones. The third type of shock wave occurs due to the installation of an aerator on spillway chutes to avoid cavitation damages $[18,19]$. Studies indicate that the aerator ramp, the ratio of lateral jet length to bottom jet length, flow depth, and Froude number have a dominant effect on shock wave intensity. The fourth type of shock wave is generated directly downstream of the overflow spillway crest. In this case, diffusion of flows takes place due to spillway piers at their tail part [6]. A number of research studies have been carried out to study the hydraulic characteristic of this kind of shock wave. Behera et al. [20] concluded that a standing wave is created at the downstream end of the pier because the confluence of the flows from the two spillway bays is at a slight angle and higher discharge. The standing wave develops directly downstream of the pier, and the shock waves travel laterally, reaching the downstream of a bucket for higher discharge $Q$ equals $810.54 \mathrm{~m}^{3} / \mathrm{s}$. These standing waves with shock waves are highly fluctuating and create additional scouring damage in the downstream spillway together with regular hydraulic jumps. Under these circumstances, such waves may be eliminated to save costs and avoid potential catastrophic hazards. Duan [21] developed a sloping tail pier to eliminate the shock wave generated on the spillway chute of a hydropower project. Later, an experimental study of [22-24] concluded that the height of shock wave depends on the ratio of approach flow depth to pier width. They performed several experiments in the horizontal channel and sloping chutes to investigate the hydraulic characteristics of a shock wave. In another study, Wu and Yan $[25,26]$ investigated the formation of a shock wave in discharging tunnel due to pier. They developed a new type of pier to control shock wave in discharge tunnel. Recently, Xue et al. [6] also developed a composite tail for the spillway pier to reduce shock wave height or eliminate the shock wave on spillway chutes 
with slope variations of $12^{\circ}$ to $20^{\circ}$. Xue et al. [6] noted that shock waves are influenced by spillway pier width and type, chute slope and flow depth in the spillway chute.

Despite many studies on the hydraulic characteristics of flow in a chute spillway, there is insufficient knowledge of the formation of shock waves. Investigations on the formation of the shock wave flow in a horizontal rectangular channel by Reinaur and Hager [22] showed that, for the state of constant flow depth $\mathrm{H}_{0}$ and constant pier width $\mathrm{b}_{\mathrm{p}}$, the height of waves and their width increase with an increase in the Froude number. Recently, it was noticed that if the depth measurements were taken perpendicularly to the chute spillway, the results would be consistent with the studies performed in the horizontal channel [23,27]. Further, $\mathrm{Wu}$ and Yan [25] investigated the hydraulic characteristics of the shock wave's formation by the pier of the discharge tunnel of the Sanbanxi hydropower station. It was observed that the primary reason for the shock wave's inception was the concavity of the water surface.

The current literature on shock waves over spillways includes a large quantity of experimental work indicating that an intense shock wave can overtop the spillway chute walls and induce vibrations in spillway structures $[25,28]$. Ultimately, such a situation disturbs the flood operation of the spillway [29-31]. The literature survey also showed the lack of research on shock wave generation at flat spillway chutes $\left(5^{0}\right.$ to $\left.10^{0}\right)$. Keeping in view the adverse effects of a shock wave, a physical model of Mohmand Dam Spillway was constructed to investigate the hydraulic characteristics and generation mechanism of shock waves on flat spillway chutes. In the end, an empirical equation was developed based on observed data to estimate shock wave height for flat slope spillway chutes.

\section{Study Area}

Mohmand dam is proposed on Swat River, approximately $37 \mathrm{~km}$ north of Peshawar and $5 \mathrm{~km}$ upstream of existing Munda Headworks in Mohmand Agency of Pakistan's Federally Administrated Tribal Area (FATA), as shown in Figure 1. The gated type of spillway is provided to pass a design flood of $27,427 \mathrm{~m}^{3} / \mathrm{s}$. It is to be located on the left abutment of the dam. It comprises seven bays (07) and a long concrete chute. The crest level of the spillway is $539 \mathrm{~m}$ amsl, whereas the maximum reservoir operating level is $563 \mathrm{~m}$ amsl. To normalize the high flow velocity ( 23 to $45 \mathrm{~m} / \mathrm{s}$ ), a double stilling basin arrangement is provided to dissipate the energy.

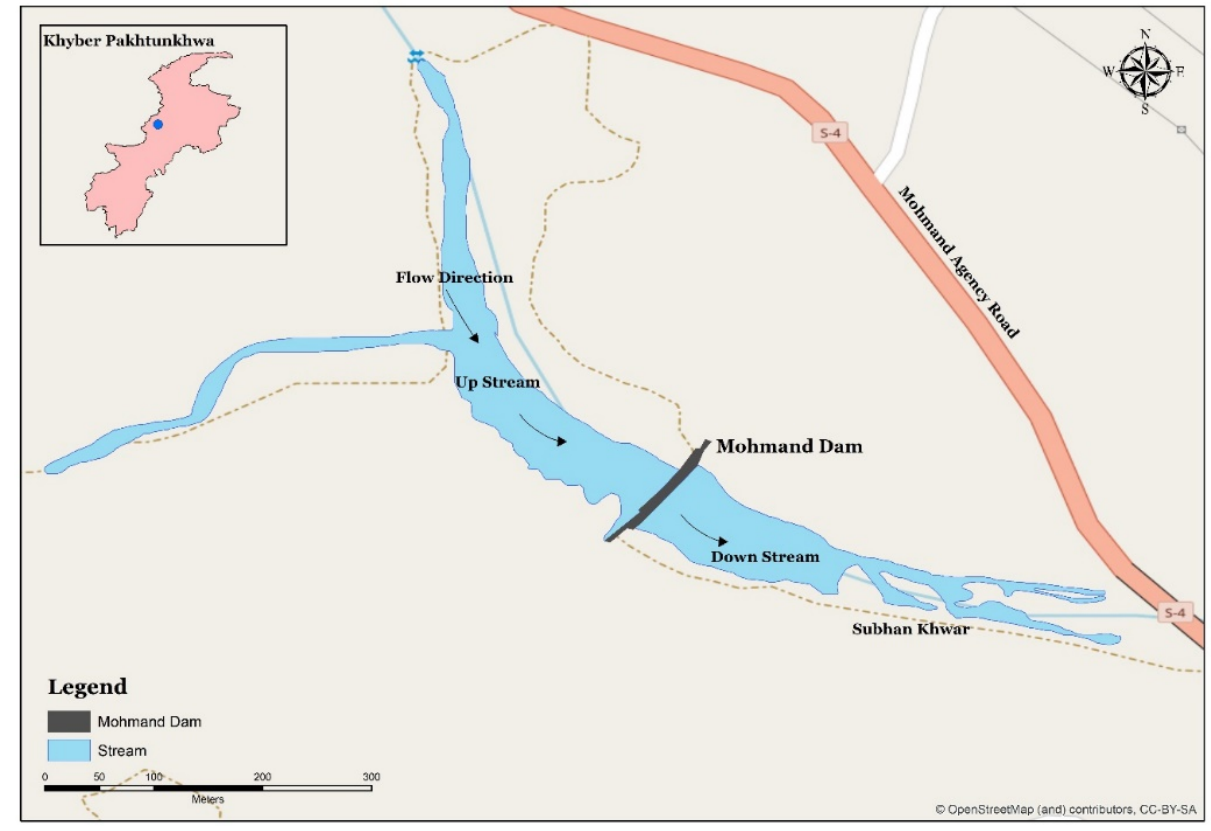

Figure 1. Location of Mohmand Dam project. 


\section{Experimental Setup}

To study the hydraulic characteristics of shock waves on flat spillway chutes, a physical model of Mohmand Dam spillway was constructed in the model tray hall of Center of Excellence in Water Resources Engineering (CEWRE), Lahore, Pakistan. The spillway model was designed based on gravity similarity criteria. It was constructed with two bays at a scale of 1:100 considering discharge and space limitations.

Each bay was equipped with radial gates. As shown in Figure 2a, the model consists of: a water tank, V-notch, a small water tank, baffle walls, a spillway control section (provided with redial gates and piers), and a spillway chute. The width of each bay and pier was 15 and $5 \mathrm{~mm}$, respectively. As depicted in Figure 2b, the tail part of the spillway pier has an elliptical or rectangular shape. The length of semi-major axis $(a)$ and chute slope $(\theta)$ were considered for this study. Details regarding geometric parameters of the pier and spillway chute slope are discussed in Table 1 below (where $a=0$ means tail part of the pier is rectangular, otherwise it is elliptical).

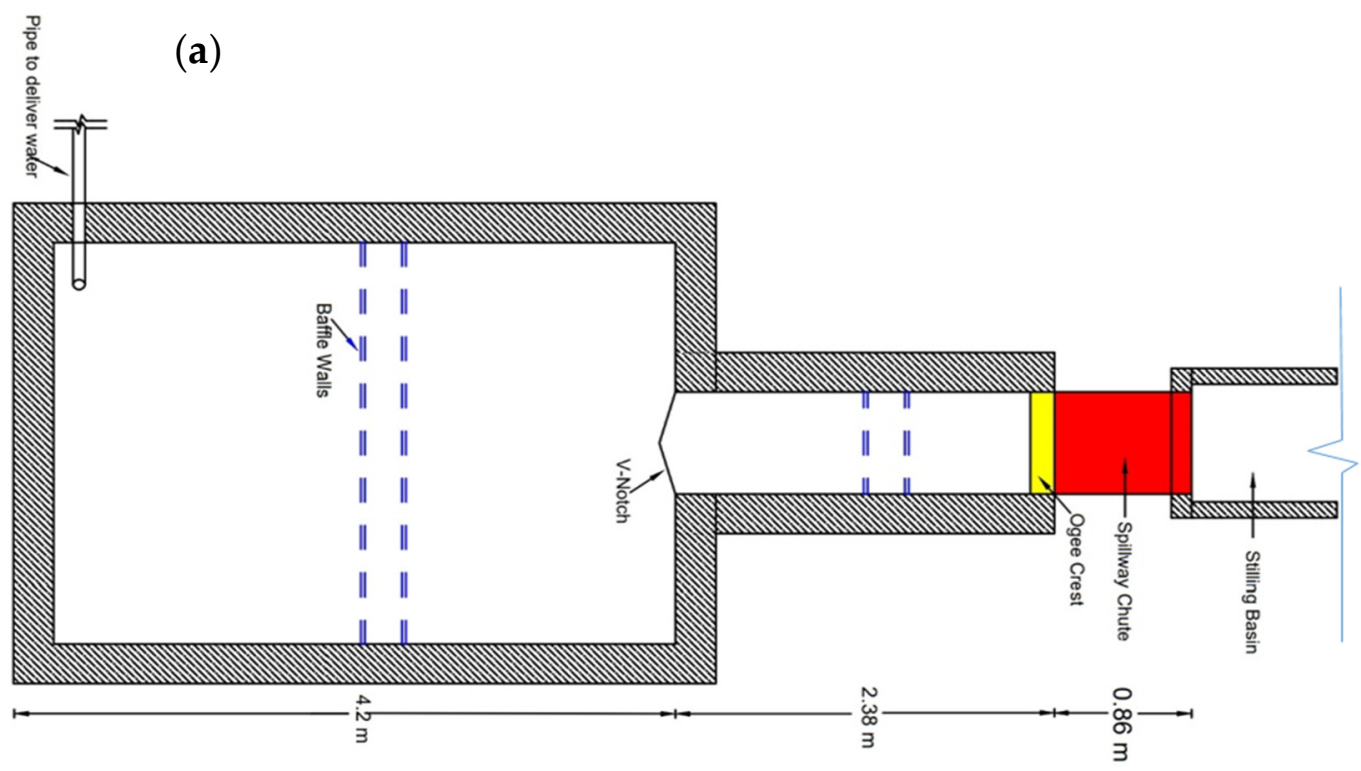

(b)

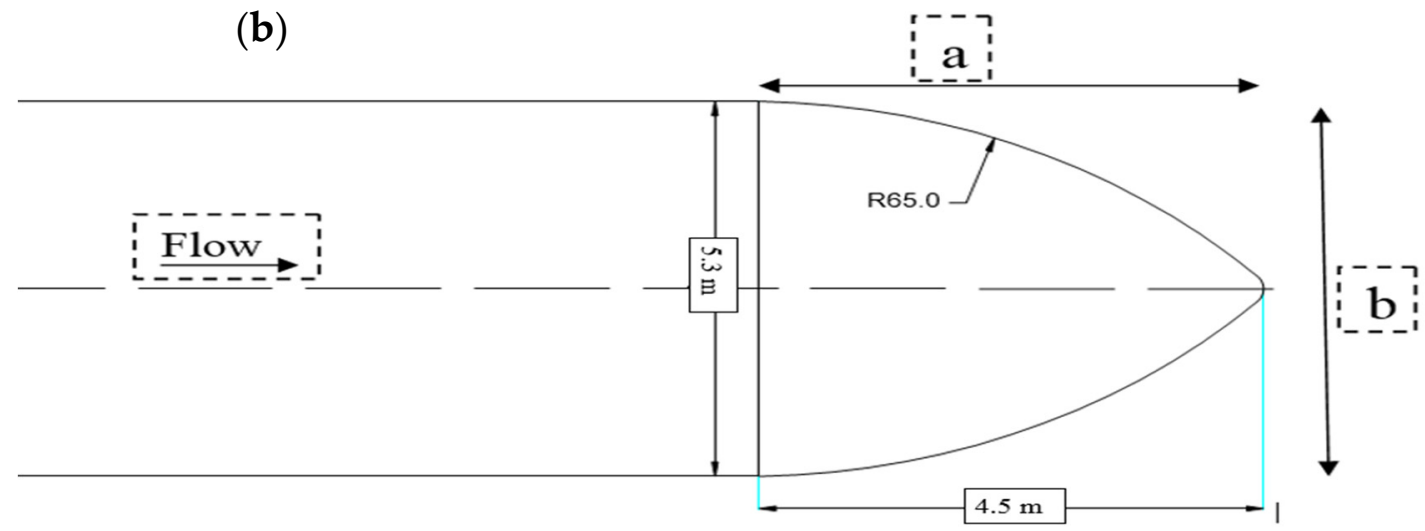

Figure 2. (a) Layout plane of the experimental setup. (b) Definition sketch for semi-major axis of spillway pier.

Table 1. Detail of geometric modifications.

\begin{tabular}{ccccc}
\hline Geometric Variables & $\mathbf{M}_{\mathbf{1}}$ & $\mathbf{M}_{\mathbf{2}}$ & $\mathbf{M}_{\mathbf{3}}$ & $\mathbf{M}_{\mathbf{4}}$ \\
\hline Spillway slope $(\theta)$ & $1: 6.5$ & $1: 6.5$ & $1: 8.5$ & $1: 8.5$ \\
Length of semi major axis $(\mathrm{m})(a)$ & 0 & 4.5 & 0 & 4.5 \\
\hline
\end{tabular}


Model operation was performed for each geometric variable shown in Table 1 at free-flow conditions by varying the reservoir levels ' $\mathrm{H}$ ' from 541 to $558 \mathrm{~m}$ amsl (with an increment of $1 \mathrm{~m}$ ). However, it was operated after its validation and dynamic similarity check, as discussed below. Hydraulic parameters observed during model operation include flow depth at upstream of the pier $\left(h_{0}\right)$, shock wave height $\left(h_{m}\right)$, depth of water surface cavity at confluence area of two defused flows $\left(h_{c}\right)$, horizontal distance before the collision of the two diffused flows $\left(I_{c}\right)$, and pressure head at the bottom of the chute $(h)$. Flow depth and pressure heads were measured using point gauge and piezometer tubes, respectively. Figure 3 shows the definition sketch for observed parameters.

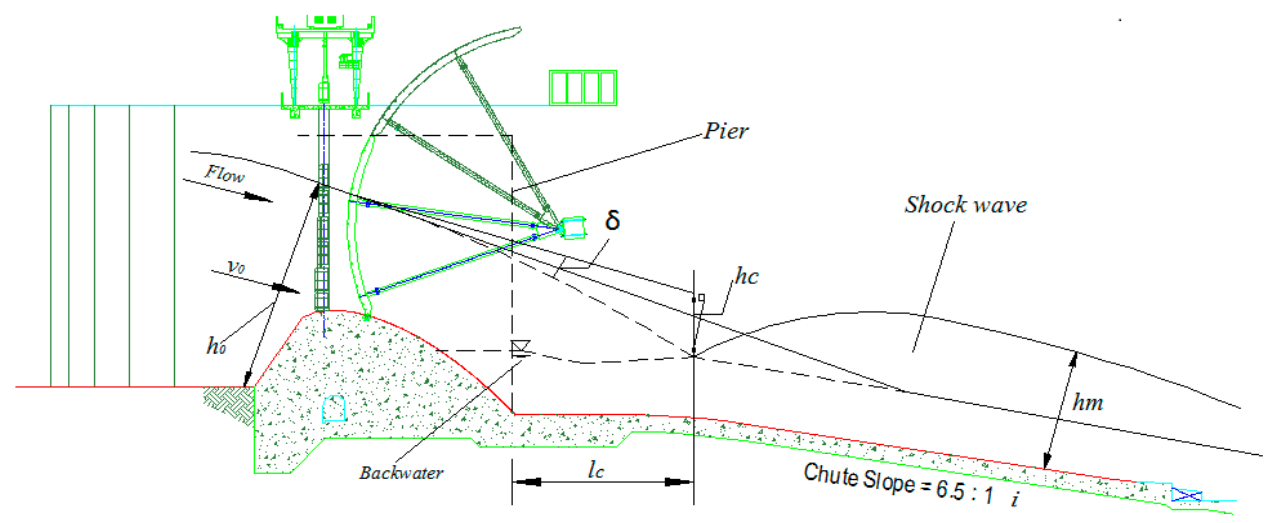

Figure 3. Definition sketch for observed hydraulic parameters.

\section{Model Validation}

Validation of the model was performed to obtain an idea about the accuracy of model results. For this purpose, observed discharge values were compared with computed ones. The comparison of observed discharge with computed discharge, as indicated in Table 2, at reservoir level of $541 \mathrm{~m}$ average mean sea level (amsl) shows only a $1.19 \%$ error, whereas at maximum reservoir levels, this difference is $3.11 \%$. Table 2 shows that the overall percentage of the difference between observed and computed values is up to $3 \%$. It indicates that the physical model is a good representative of a prototype.

Table 2. Comparison between observed and computed discharge.

\begin{tabular}{ccccc}
\hline Sr. No. & $\begin{array}{c}\text { Reservoir Level } \\
\text { amsl }(\mathbf{m})\end{array}$ & $\begin{array}{c}\text { Observed Discharge } \\
\left(\mathbf{m}^{\mathbf{3}} \mathbf{/ s}\right)\end{array}$ & $\begin{array}{c}\text { Computed Discharge } \\
\left(\mathbf{m}^{\mathbf{3}} \mathbf{/ s}\right)\end{array}$ & Error $\mathbf{( \% )}$ \\
\hline 1 & 539 & 0 & 0 & 0 \\
2 & 541 & 156.99 & 155.14 & 1.19 \\
3 & 543 & 453.08 & 446.8 & 1.41 \\
4 & 545 & 848.05 & 837.4 & 1.27 \\
5 & 547 & 1337.75 & 1314.28 & 1.79 \\
6 & 549 & 1902.02 & 1870.5 & 1.69 \\
7 & 551 & 2550.89 & 2498.5 & 2.10 \\
8 & 558 & 5052.27 & 5214.2 & 3.11 \\
\hline
\end{tabular}

\section{Dynamic Similarity of Model}

Dynamic similarity exists between the model and prototype if the ratio of inertial to gravity forces at some point in the model is the same at the corresponding point of the prototype. Froude similarity law is used in problems where gravity is important, i.e., in free-surface flows such as in case of flow over the spillway, weir, under sluice gates, open channel, etc. In the current study, Froude's model law was applied. The Froude number observed near the control section of the spillway at the reservoir level of $558 \mathrm{~m}$ amsl was 0.730 , whereas the calculated value was 0.725 . This indicates that the model is dynamically similar to the prototype. 


\section{Height of Shock Wave}

The height of the shock wave provides an important reference for the computation of optimal height of spillway sidewalls. In the current study, shock wave height was computed by operating the Mohmand Dam Spillway model for geometric variables as shown in Table 1. The results show (Figure 4) that in the beginning, the height of the shock wave for all geometric variables $\left(\mathrm{M}_{1}\right.$ to $\left.\mathrm{M}_{4}\right)$ was almost the same, but with the further increase in reservoir level (above $547 \mathrm{~m}$ amsl), a clear difference in shock wave height between $\mathrm{M}_{1}$ and $\mathrm{M}_{2}$ and $\mathrm{M}_{3}$ and $\mathrm{M}_{4}$ was noticed. For $\mathrm{M}_{1}$, the shock wave height was increased with the increase in reservoir level up to $551 \mathrm{~m}$ amsl, and after that, the shock wave height decreased with a further increase in reservoir level. For $\mathrm{M}_{2}$, the shock wave height increased thoroughly with the increase in the reservoir level. The same trend was observed in the case of $\mathrm{M}_{3}$ and $\mathrm{M}_{4}$. It is also visible from Figure 4 that shock wave heights are also almost the same at the maximum reservoir level. It is noted that when discharge increases, the backwater flow also increases, and the distance between the two diffused flows and pier decreases, which affect the shock wave height at maximum discharge or reservoir level. A clear difference in shock wave height between $M_{1}$ and $M_{2}$ and $M_{3}$ and $\mathrm{M}_{4}$ (from reservoir level 547 to $557 \mathrm{~m}$ amsl) indicates the impact of the extended part of the pier installed at its tail end (semi-major axis length).

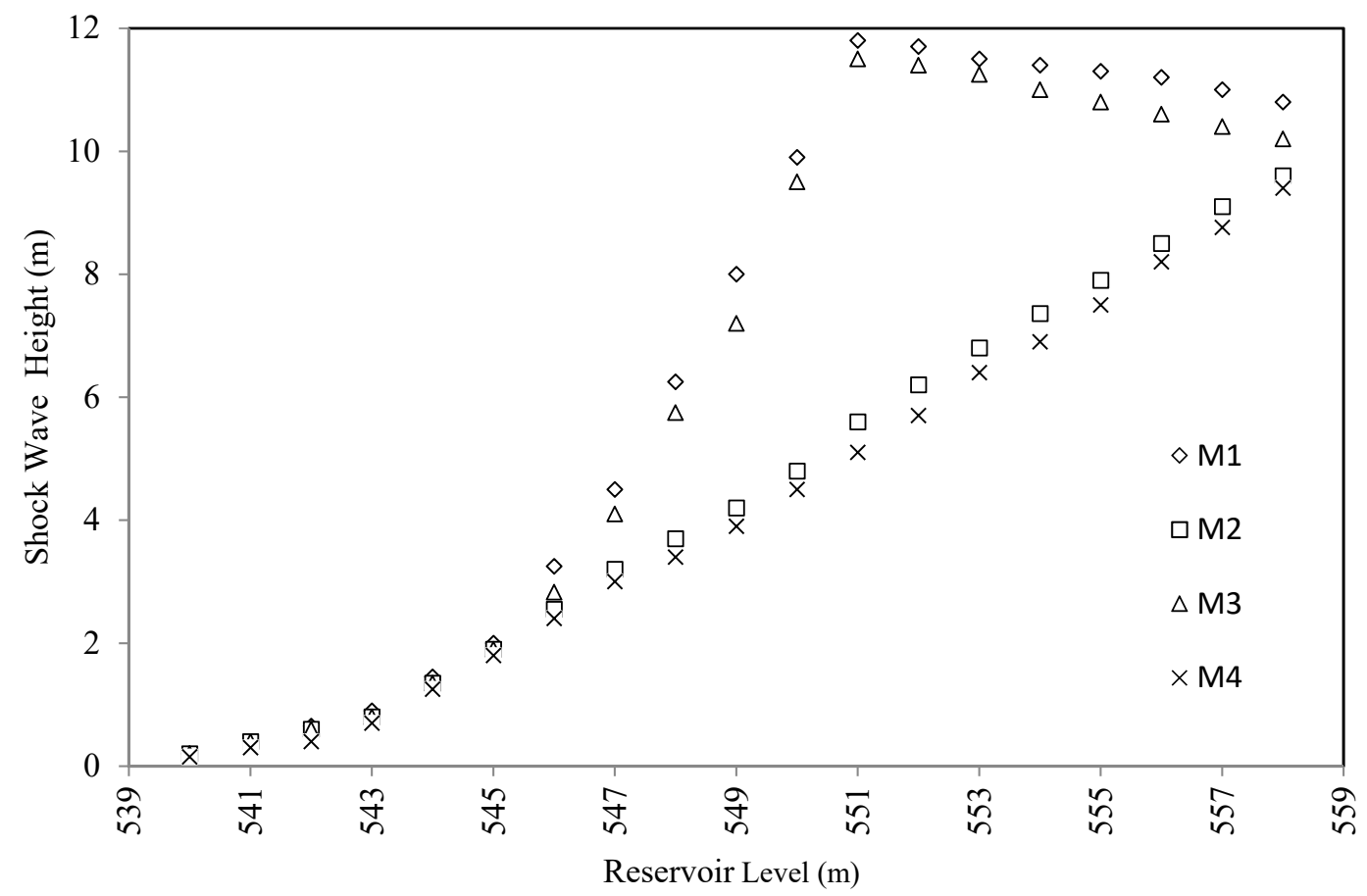

Figure 4. Observed shock wave heights for all geometric variables.

Figure 5a-c presents the profile view of shock wave formation at reservoir levels of 547, 549 and $551 \mathrm{~m}$ amsl, respectively, without geometric modification $(a=0)$, while Figure $5 \mathrm{~d}-\mathrm{f}$ shows the profile view of shock wave formation at above-mentioned reservoir levels with geometric modification $(a=45 \mathrm{~mm})$. As shown in Figure $5 \mathrm{a}, \mathrm{d}$, for the same reservoir level, i.e., at $547 \mathrm{~m}$ amsl, the shock wave height is low in the case of ' $\mathrm{d}$ ' as compared to case ' $\mathrm{a}$ ' due to geometric modification. A similar trend can be noted at other reservoir levels (549 and $551 \mathrm{~m}$ amsl) from Figure 5. 

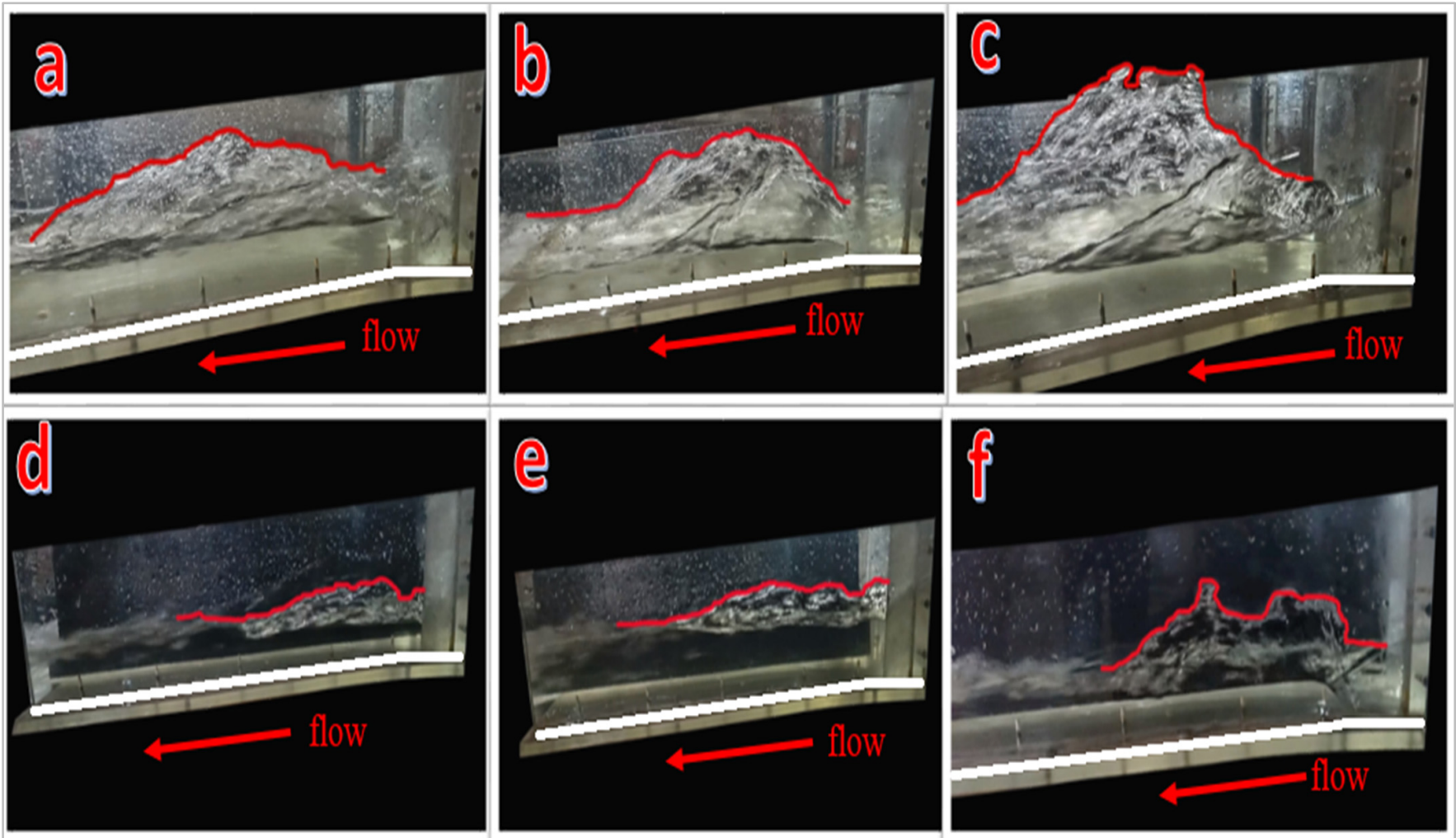

Figure 5. Profile views of shock wave formation for $\mathrm{M}_{3}(\mathbf{a}-\mathbf{c})$ and $\mathrm{M}_{4}(\mathbf{d}-\mathbf{f})$.

\section{Evaluation of Cavity Angle and Diffused Flow Pressure}

The flow was diffused laterally behind the pier because there was no constraint effect due to the pier sidewall. A cavity with backwater in the tail part of the pier was generated by the diffused flow, as shown in Figure 6a,b. Based on the experimental observations, it was noted that the size of the cavity can significantly affect the shock wave formation. The ratio of the horizontal diffusion distance to the depth of the water surface concave $\left(I_{c} / h_{c}\right)$ can be used to describe the cavity form. Thus, the experimental data were used to investigate the relationship between the ratio of the shock wave height to the width of the pier $\left(h_{m} / b\right)$ and $I_{c} / h_{c}$. The value of the coefficient of determination is 0.85 , which indicates that there is a significant correlation between them (Figure 7), and an exponential relationship can be written as follows:

$$
\frac{h_{m}}{b}=3.0018 \exp \left(-0.493 \frac{I_{c}}{h_{c}}\right)
$$

As per Figure 3, the equation for the dropping angle $(\delta)$ can be given as under:

$$
\cot \delta=\frac{I_{c}}{h_{c}} \frac{1}{\cos ^{2} \theta}+\tan \theta
$$

In Equation (2), $\theta$ represents the spillway chute angle. By rearranging Equation (2) and substituting it into Equation (1), we can obtain:

$$
\frac{h_{m}}{b}=3.0018 \exp \left[-0.493(\cot \delta-\tan \theta) \cdot \cos ^{2} \theta\right]
$$

It can be noted from Equation (3) that $h_{m} / b$ increases with the increase in dropping angle $(\delta)$ when the spillway chute slope $(\theta)$ and the width of the pier $(b)$ remain constant, which means that the rooster tail's height is significantly affected by the dropping angle. 

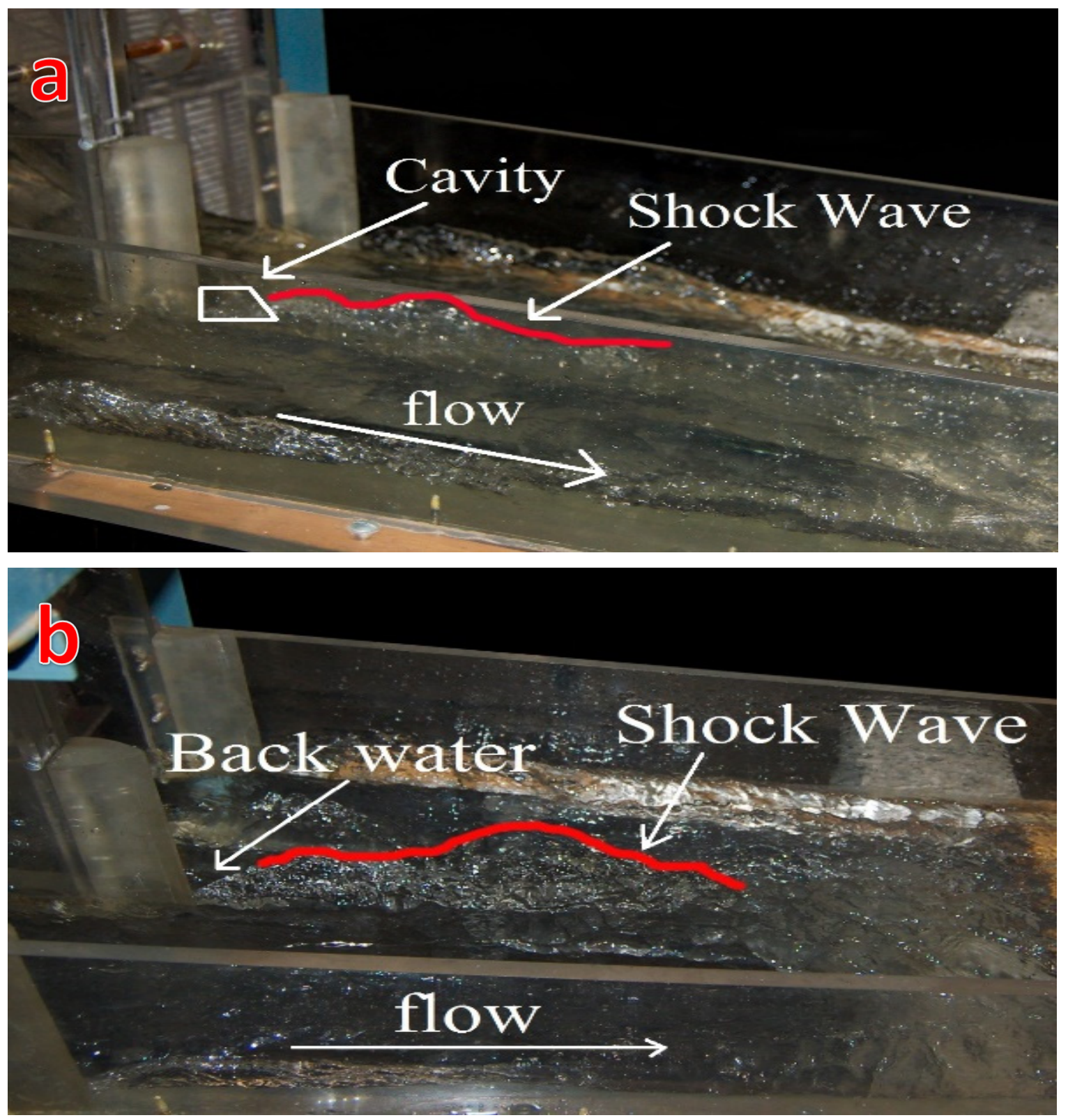

Figure 6. Cavity formation behind the pier. (a) Longitudinal view. (b) Plan view.

\section{Pressure Energy}

The other hydraulic parameter that induced the shock wave was the gathering pressure generated by the joint flow. During that process, the kinetic energy of the diffused flow is converted into pressure energy and is transported to the bottom, subsequently. Thus, variations in the pressure of the spillway bottom may be used to reflect the intensity of the shock wave.

The pressure distributions along the length of the chute for $\mathrm{M}_{3}$ and $\mathrm{M}_{4}$ are shown in Figures 8 and 9 , respectively, in which the origin of the coordinate axis $(x)$ is at the tail of the pier, ' $\mathrm{p}$ ' is the spillway chute pressure, and ' $\gamma$ ' is the bulk density of water $\left(\gamma=9.8 \mathrm{kN} / \mathrm{m}^{3}\right)$. It can be concluded from Figures 8 and 9 that at different water heads $(\mathrm{H})$, all the pressure peaks occur at the bottom near the tail part of the pier due to the formation of a shock wave. Moreover, the peak values for $\mathrm{M}_{4}$ are slightly less as compared to $\mathrm{M}_{3}$ due to extension in the tail part of the pier (length of semi-major axis). 


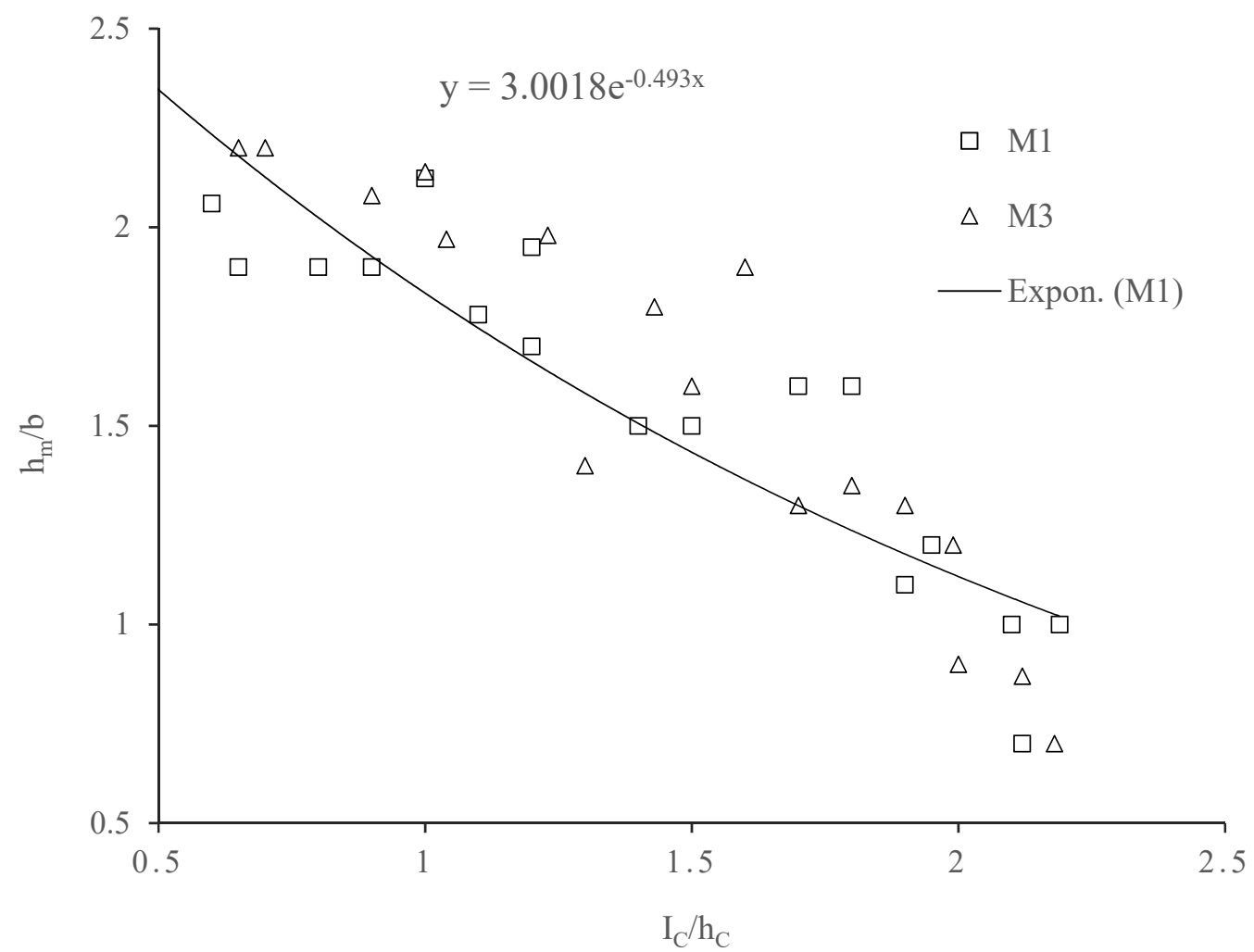

Figure 7. Relationship between the ratio of the rooster tail height to the width of the pier $\left(h_{m} / b\right)$ and $I_{\mathcal{c}} / h_{c}$.

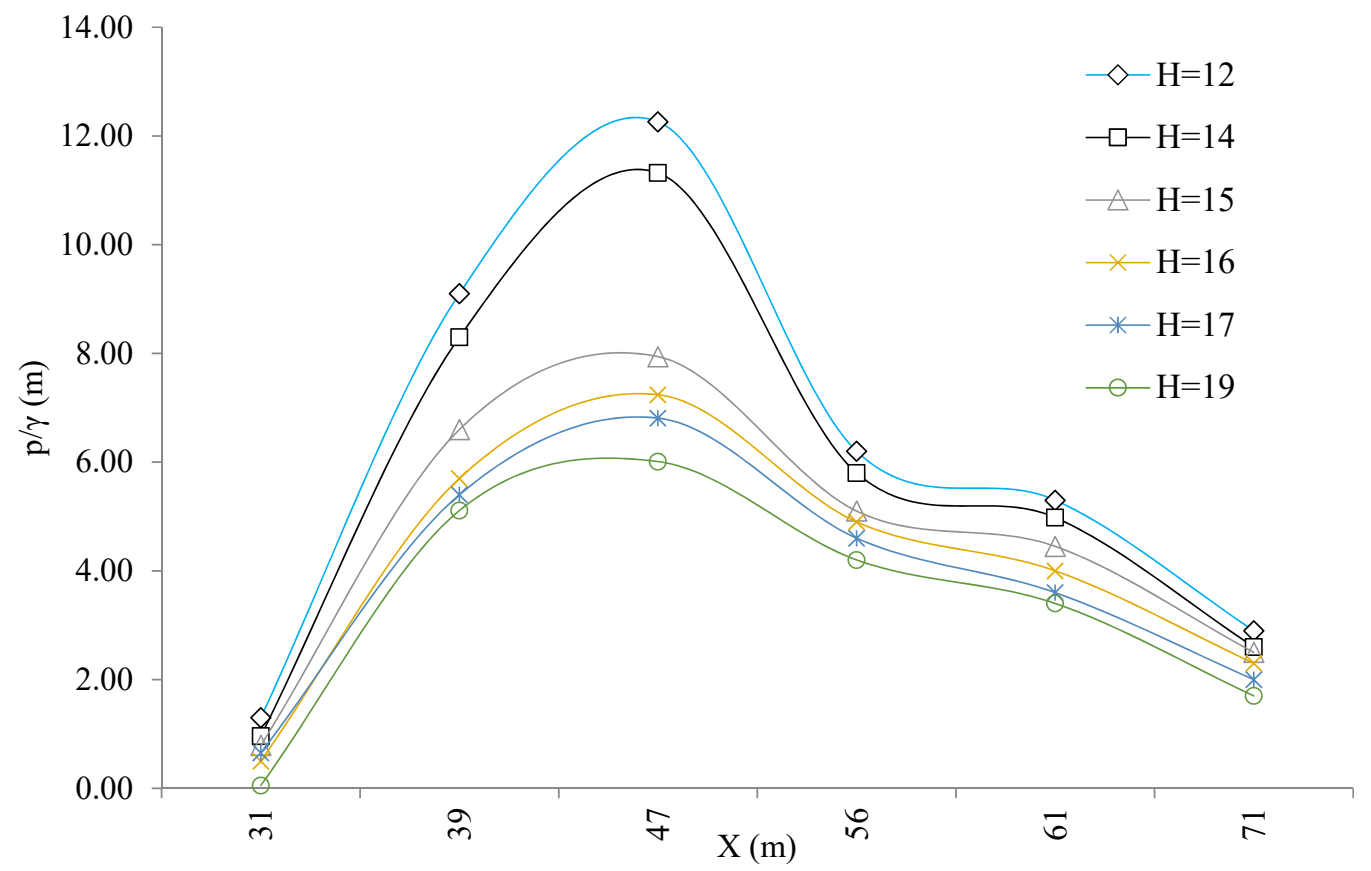

Figure 8. Spillway chute pressure distribution for $\mathrm{M}_{3}$. 


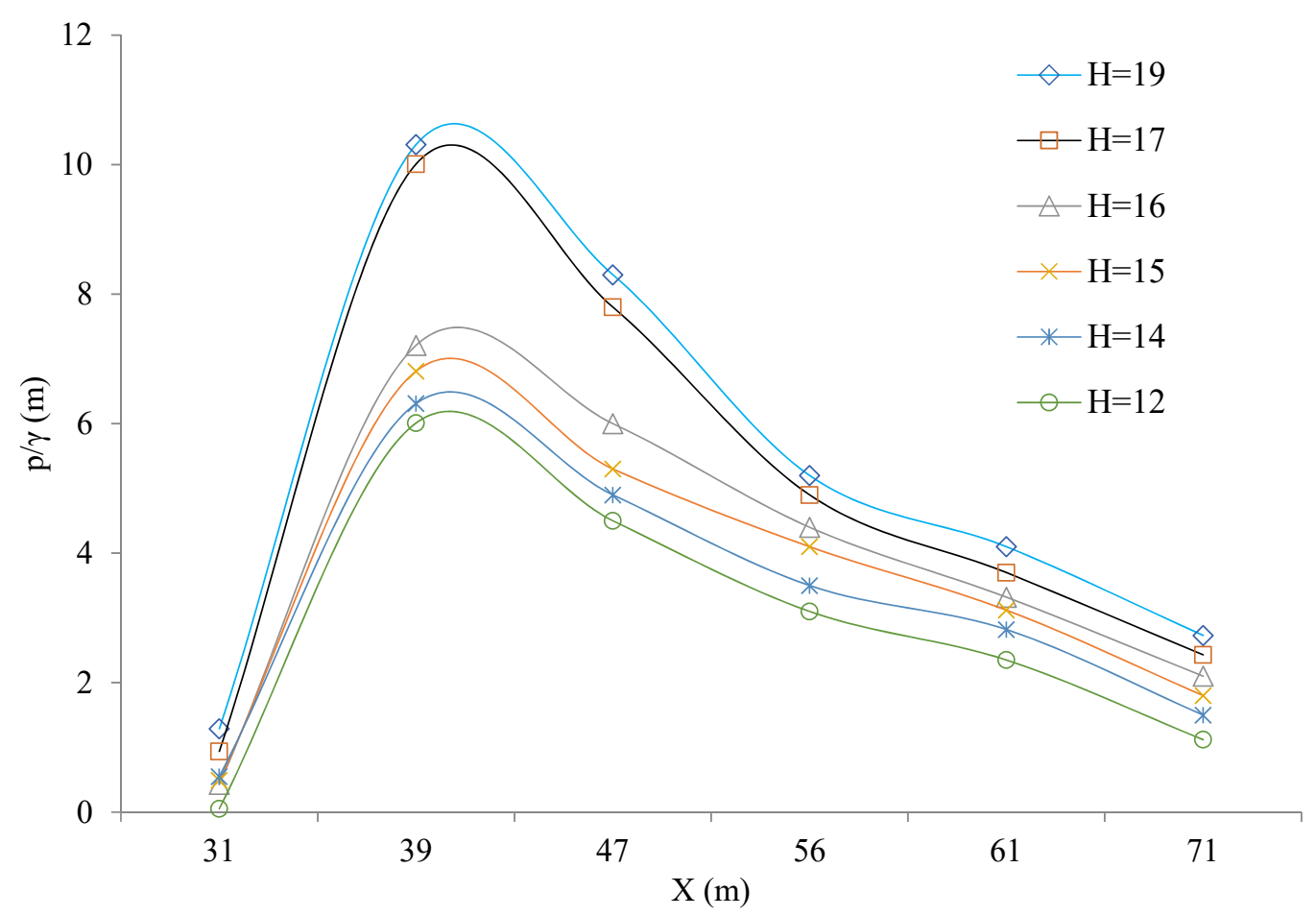

Figure 9. Spillway chute pressure distribution for $\mathrm{M}_{4}$.

\section{Evaluation of Cavity Angle and Diffused Flow Pressure}

The equation presented by Xue et al. (2018) was modified for estimation of the shock wave height on flat spillway chutes $\left(5^{\circ}\right.$ to $\left.10^{\circ}\right)$.

$$
\frac{h_{m}}{h_{o}}=2.5\left(\frac{h_{o}}{b}\right)^{0.5} \exp \left(-\frac{c_{1} a}{h_{o}}-c_{2} i\right)
$$

In the above equation, ' $c{ }_{1}^{\prime}$ and ' $c{ }_{2}$ ' are experimental coefficients, whereas ' $i$ ' represents the slope ratio of the bottom. Analysis was performed on MiniTab software to examine the suitability of experimental coefficients for experimental data collected from the model study. Minitab is the statistical software that helps in taking out the complexities of statistical calculations. The experimental data were divided into training and testing values. Seventy percent $(70 \%)$ of values were used as training values, while thirty percent $(30 \%)$ values were considered as testing values. Training data were used to modify the Xue et al. (2018) equation. The modified form of Equation (4) is shown below.

$$
\frac{h_{m}}{h_{o}}=2.5\left(\frac{h_{o}}{b}\right)^{0.5} \exp \left(-\frac{0.78 a}{h_{o}}-13.67 i\right)
$$

Computed values of shock wave height using Equation (5) were correlated with the testing values (observed data) to find the coefficient of determination $\left(\mathrm{R}^{2}\right)$. Figure 10 shows that the coefficient of determination for computed and observed data of shock wave height is 0.91 , which indicates that data is in good correlation. Hence, the equation developed (Equation (5)) through this study can be used for the estimation of shock wave height generated on flat spillway chutes $\left(5^{\circ}\right.$ to $\left.10^{\circ}\right)$. 


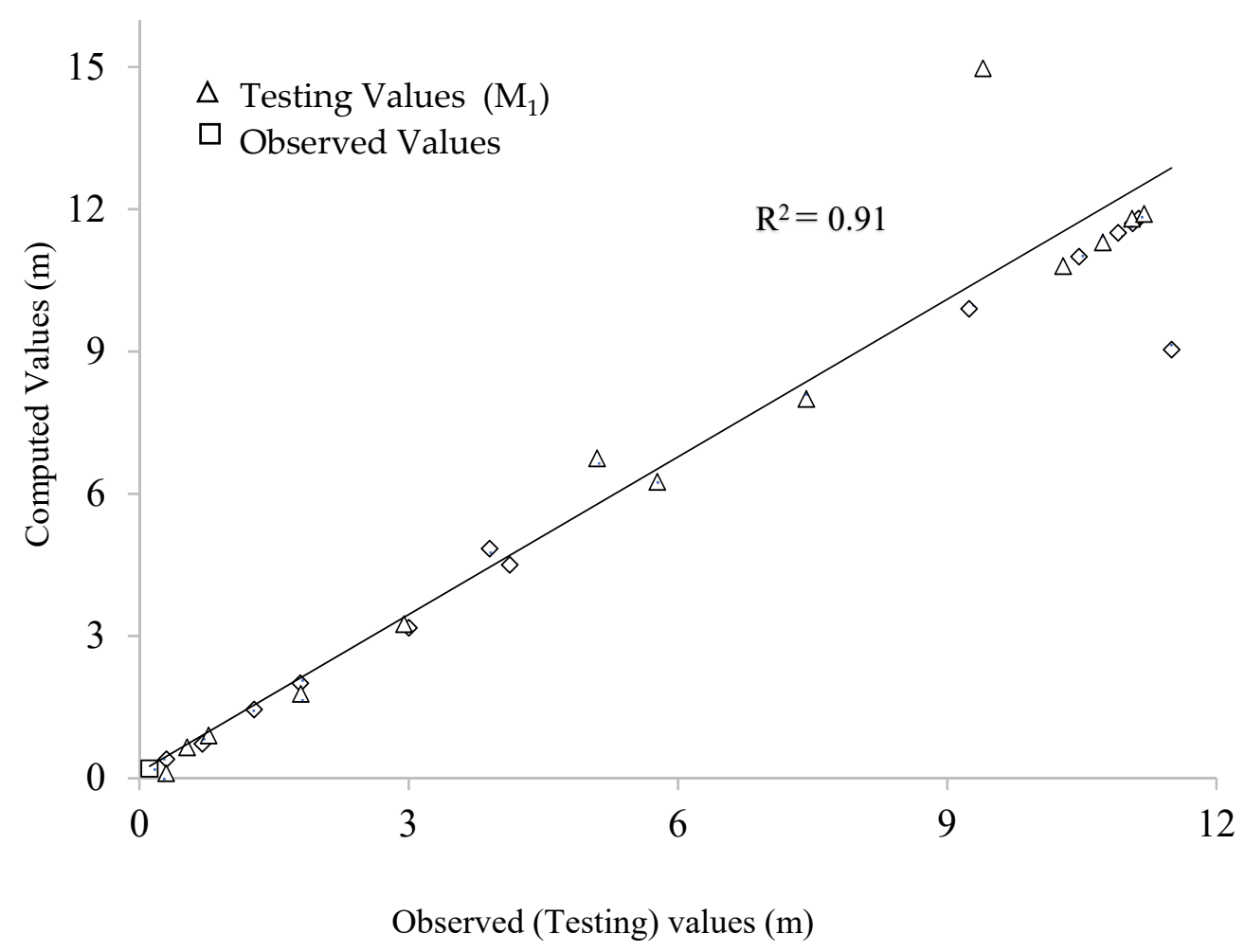

Figure 10. Plot between observed and computed shock wave height.

\section{Conclusions}

A physical study was performed on a flat spillway with varying geometric parameters of pier and spillway chute slope. While different chute configurations were tested, the focus of the study was on the hydraulic characteristics and generation mechanism of a shock wave on flat spillway chutes $\left(5^{\circ}\right.$ to $\left.10^{\circ}\right)$. The spillway model was designed based on gravity similarity criteria. It was constructed with two bays at a scale of 1:100 considering discharge and space limitations.

The study results showed that shock wave height was slightly decreased with a decrease in spillway chute slope. However, extension in the tail part of the spillway pier (semi-major axis length) caused a further reduction in shock wave height. Overall, a 26\% reduction in shock wave height was noted due to the extended part of the spillway pier. The dropping angle of diffused flow significantly affected the shock wave height. It was noted that shock wave height is directly proportional to the dropping angle of diffused flow. Variation in pressure energy along the spillway chute indicated the intensity of shock wave. Pressure peaks were observed near the tail part of the spillway pier due to the formation of a shock wave. In this study, an empirical equation was developed to estimate the shock wave height, which can be used to estimate the shock wave height at the flat spillway chute, varying from $5^{0}$ to $10^{0}$. Lastly, the main goal of the experiments was to support the planning of shock waves' adverse effects on spillway operations, therefore, the currently reduced-scale experiments may apply to prototype scale, considering the extension in the tail part of the spillway pier along with the reduction in chute slope for the elimination of shock waves.

Author Contributions: Conceptualization, M.K.S. and M.A.U.R.T.; Data curation, M.K.S., R.F. and H.K.J.A.; Formal analysis, M.K.S. and F.U.H.; Investigation, A.W.M.N.; Methodology, M.K.S., M.A.U.R.T., I.A. and N.M.; Validation, M.I.S.; Writing—original draft, M.K.S., M.A.U.R.T. and R.F.; Writing-review \& editing, M.A.U.R.T. and R.F. All authors have read and agreed to the published version of the manuscript.

Funding: This research received no external funding. 
Institutional Review Board Statement: No applicable.

Informed Consent Statement: No applicable.

Data Availability Statement: No applicable.

Acknowledgments: This study is supported by Centre of Excellence in Water Resources Engineering (CEWRE) UET, Lahore and WAPDA model study cell, Nandipur, Gujranwala Pakistan.

Conflicts of Interest: The authors declare no conflict of interest.

\section{References}

1. Lee, K.H. Simulation of Dam-Breach Outflow Hydrographs Using Water Level Variations. Water Resour. Manag. 2019, 33, $3781-3797$. [CrossRef]

2. Eghlidi, E.; Barani, G.A.; Qaderi, K. Laboratory Investigation of Stilling Basin Slope Effect on Bed Scour at Downstream of Stepped Spillway: Physical Modeling of Javeh RCC Dam. Water Resour. Manag. 2020, 34, 87-100. [CrossRef]

3. Jie, Z.; Zhiming, C.; Matahel, A.; Zubayed, R.; Mark, W. Transitional Flow Analysis at Prototype Gated Spillways in South Florida. J. Irrig. Drain. Eng. 2021, 147, 4020042. [CrossRef]

4. Matahel, A.; Zhiming, C. Generalized Flow Rating Equations at Prototype Gated Spillways. J. Hydraul. Eng. 2009, 135, 602-608. [CrossRef]

5. Al-Mansori, N.J.H.; Alfatlawi, T.J.M.; Hashim, K.S.; Al-Zubaidi, L.S. The Effects of Different Shaped Baffle Blocks on the Energy Dissipation. Civ. Eng. J. 2020, 6, 961-973. [CrossRef]

6. Xue, H.; Diao, M.; Ma, Q.; Sun, H. Hydraulic Characteristics and Reduction Measure for Rooster Tails Behind Spillway Piers. Arab. J. Sci. Eng. 2018, 43, 5597-5604. [CrossRef]

7. Vayghan, V.H.; Mohammadi, M.; Ranjbar, A. Experimental Study of the Rooster Tail Jump and End Sill in Horseshoe Spillways Civ. Eng. J. 2019, 5, 871-880. [CrossRef]

8. Vischer, D.L.; Hager, W.H.; Cischer, D. Intake structures. In Dam Hydraulics; John Wiley Sons: Chichester, UK, 1998; pp. 215-232.

9. Ghadimi, P.; Dashtimanesh, A.; Zamanian, R.; Feizi Chekab, M.A.; Mirhosseini, S.H.R. Rooster tail depression by originating a modified transom stern form using a Reynolds averaged Navier Stokes solver. Sci. Iran. 2015, 22, 765-777.

10. Salazar, F.; San-Mauro, J.; Celigueta, M.Á.; Oñate, E. Shockwaves in spillways with the particle finite element method. Comput. Part. Mech. 2020, 7, 87-99. [CrossRef]

11. JING, L.I.; XIANG, Z. Study on Formation Mechanism of Shock Wave after Gate Pier. In Proceedings of the E-Proceedings of the 38th IAHR World Congress, Panama City, Panama, 1-6 September 2019.

12. Huang, G.-b.; Hu, H.; Wang, C.-h.; Du, L. Shock waves and water wing in slit-type energy dissipaters. J. Hydrodyn. 2017, 29, 504-509. [CrossRef]

13. Rajaratnam, N. Skimming flow in stepped spillways. J. Hydraul. Eng. 1990, 116, 587-591. [CrossRef]

14. Tuna, M.C.; Emiroglu, M.E. Effect of step geometry on local scour downstream of stepped chutes. Arab. J. Sci. Eng. 2013, 38, 579-588. [CrossRef]

15. Toombes, L.; Wagner, C.; Chanson, H. Flow patterns in nappe flow regime down low gradient stepped chutes. J. Hydraul. Res. 2008, 46, 4-14. [CrossRef]

16. Carnacina, I.; Kurdistani, S.M.; Palermo, M.; Pagliara, S. El Chaparral dam model: Rooster tail formation on high sloped spillway. In Proceedings of the 3rd International Junior Researcher and Engineer Workshop on Hydraulic Structures, Brisbane, Australia, 2-3 May 2010; Volume 10, pp. 65-73.

17. Chanson, H. Prediction of the transition nappe/skimming flow on a stepped channel. J. Hydraul. Res. 1996, 34, 421-429. [CrossRef]

18. Najafi, M.R.; Zarrati, A.R. Numerical simulation of air-water flow in gated tunnels. Proc. Inst. Civ. Eng. Water Manag. 2010, 163, 289-295. [CrossRef]

19. Pagliara, S.; Kurdistani, S.M.; Roshni, T. Rooster tail wave hydraulics of chutes. J. Hydraul. Eng. 2011, 137, 1085-1088. [CrossRef]

20. Behera, J.; Kar, A.K.; Khamari, A. Scour at the downstream of Ghatakeswar spillway using non-cohesive hydraulic model. ISH J. Hydraul. Eng. 2021, 1-11. [CrossRef]

21. Duan, W.J. The submerged sloping-tail pier-An effective measure to eliminate the crown of jumping flow. J. Sichuan Univ. Eng. Sci. Ed. 1982, 1, 63-67.

22. Reinauer, R.; Hager, W.H. Supercritical flow behind chute piers. J. Hydraul. Eng. 1994, 120, 1292-1308. [CrossRef]

23. Reinauer, R.; Hager, W.H. Pier waves in sloping chutes. Int. J. Hydropower Dams 1997, 4, 100-103.

24. Reinauer, R.; Hager, W.H. Shockwave in air-water flows. Int. J. Multiph. flow 1996, 22, 1255-1263. [CrossRef]

25. Wu, J.; Cai, C.; Wei, J.I.; Ruan, S. Hydraulic characteristics of water-wings for the middle-pier of a discharge tunnel. J. Hydrodyn. Ser. B 2006, 18, 567-571. [CrossRef]

26. $\mathrm{Wu}, \mathrm{J} . ;$ Yan, Z. Hydraulic characteristics of bottom underlay-type pier for water-wing control. J. Hydrodyn. 2008, 20, 735-740. [CrossRef]

27. Mooselu, M.G.; Nikoo, M.R.; Rayani, N.B.; Izady, A. Fuzzy multi-objective simulation-optimization of stepped spillways considering flood uncertainty. Water Resour. Manag. 2019, 33, 2261-2275. [CrossRef] 
28. Sheng, C.; Jian, Z.; Ming, H.; Hazrati, A. Experimental study on water-wing characteristics induced by piers in flood drainage culverts. Sci. Iran. 2013, 20, 1320-1326.

29. Shao, Z.; Jahangir, Z.; Muhammad Yasir, Q.; Mahmood, S. Identification of potential sites for a multi-purpose dam using a dam suitability stream model. Water 2020, 12, 3249. [CrossRef]

30. Zhan, X.; Qin, H.; Liu, Y.; Yao, L.; Xie, W.; Liu, G.; Zhou, J. Variational Bayesian Neural Network for Ensemble Flood Forecasting. Water 2020, 12, 2740. [CrossRef]

31. Farooq, R.; Ahmad, W.; Hashmi, H.N.; Saeed, Z. Computation of Momentum Transfer Coefficient and Conveyance Capacity in Asymmetric Compound Channel. Arab. J. Sci. Eng. 2016, 41, 4225-4234. [CrossRef] 